\title{
Perspectives of Stem Cell-Derived Microglia for Medicine
}

\author{
Kristin Roy, Clara Beutner and Harald Neumann \\ University of Bonn \\ Germany
}

\section{Introduction}

Microglia, the resident immune cells of the central nervous system (CNS), are responsible for the innate brain immune defence. The exact origin of microglia is still unclear, but several reports suggest that microglia are of myeloid origin (Chan et al., 2007). They appear for the first time at an early embryonic state in the neuroepithelium and populate the brain from the blood in a second perinatal phase. Under pathological conditions or infections, microglia migrate to the affected tissue. On site, they change their phenotype to a proinflammatory cell type, release cytotoxic molecules such as reactive oxygen species to fight against microbes or clear tissue debris after sterile injury. Microglia also phagocyte oncogenically transformed brain cells and are able to activate additional immune cells. Proinflammatory microglial cells are also involved in the progression of neurodegenerative diseases.

Research on microglia is mainly performed on primary cells. However, only a limited amount of murine or human microglial cells can be obtained from the brain tissue, thus complicating investigations of drug screenings or new cell therapy approaches that are requiring a high number of cells. For this reason, stem cell-derived microglia represent a useful tool for further studies to elucidate the role of microglia in diseases and therapeutical approaches. Data from others and our laboratory show that microglial precursor cell lines can be obtained from mouse embryonic stem cells or human induced pluripotent stem cells via a neural differentiation protocol. Human microglial cell lines open new alternatives for drug screening, combating cancer and regenerative approaches for neurological diseases.

\section{Microglia in neuroinflammation and neurodegeneration}

The CNS contains two major cell types: neurons and glial cells. Neurons build a network throughout the nervous system and forward information through electrical conduction. Glial cells are only indirectly involved in the conduction process, but play an essential supportive role to neurons. Glial cells of the CNS can be subdivided into two main classes: macroglia consisting of astrocytes and oligodendrocytes and microglia. Microglia are the only immune competent cells in the intact CNS. They were defined by Ramon Y Cajal in 1913 as a third group of cells in the CNS and termed mesoglia (Rezaie and Male, 2002). Microglial cells were further characterized by Rio del Hortega using silver carbonate staining (del Rio-Hortega, 1933). He defined the term microglia and proposed that they can 
change their morphology dependent on their activation state. Microglial distribution varies by brain region, but they predominate in the grey matter with highest concentrations in the hippocampus, the substantia nigra, the olfactory telencephalon and the basal ganglia (Block et al., 2007). In the healthy CNS the so called 'resting' microglia display a ramified morphology. However, microglial cells are not resting at all, but continuously survey their microenvironment with their processes. Time-laps imaging using in vivo two-photon microscopy revealed that the somata of microglial cells remain stably localized whereas the processes are remarkable motile (Nimmerjahn et al., 2005). The microglial processes show continuous cycles of withdrawal and new formation, thereby scanning the whole brain parenchyma every few hours. Upon immunological stimuli or in response to brain injuries microglia become activated and migrate towards the stimuli. At the lesion site they change their phenotype from a ramified to an amoeboid morphology, clear debris and apoptotic cells and promote tissue repair. It was reported that microglia increase neuronal survival through the release of trophic and anti-inflammatory factors (Block et al., 2007; Streit, 2002). In their activated state microglia up-regulate several surface molecules such as CD14, major histocompatibility complex (MHC) molecules, complement receptors and chemokine receptors (Rock et al., 2004). Furthermore, pro-inflammatory activated microglia release a wide range of soluble factors like superoxide, nitric oxide and tumor necrosis factor-a (TNFa), which have neurotoxic effects on neurons. It seems that microglia have both, neuroprotective and neurodestructive functions. In contrast to acute CNS injuries, chronic diseases are characterized by slow progressive neurodegeneration that takes years to develop (Streit, 2002). There is strong evidence that microglial cells are involved in a wide range of neurodegenerative diseases (Block and Hong, 2005) like Alzheimer's disease (AD), Parkinson's disease (PD), amyotrophic lateral sclerosis (ALS) and Huntington's disease (HD). Actually, AD was one of the first neurodegenerative diseases associated with neurotoxic microglia (Block and Hong, 2005). AD is a neurodegenerative disorder leading to cognitive, memory and behavioral impairments. The pathological hallmark of AD consists of cortical atrophy with accumulation of extracellular deposits of amyloid $\beta(A \beta)$ in senile plaques and intracellular neurofibrillary tangles (NFT) of hyperphosphorylated tau protein in the cerebral cortex (De Strooper and Annaert, 2000). Senile A $\beta$ plaques recruit and activate microglia, which in turn produce pro-inflammatory factors that act neurotoxic on neurons. Damaged neurons activate microglia independent of the mode of damage. Finally, this leads to neurotoxin producing microglia resulting in a perpetuating toxicity.

\section{Origin and sources of microglia}

During embryonic development gastrulation conduces to the creation of the three germ layers: ectoderm, mesoderm and endoderm (Arnold and Robertson, 2009). The ectoderm gives raise to the peripheral and central nervous system as well as to the epidermis structures. The mesoderm which is located between the endoderm and ectoderm develops into blood, muscles, bone, cartilage, notochord and the connective tissue. Organs associated with the digestive system such as pancreas, liver and the epithelium of the digestive and respiratory system are of endodermal origin.

The origin of microglia is still under debate due to the lack of a specific microglial marker. There are different hypotheses about the origin of microglia. In previous times some scientists held the view that microglia are of neuroectodermal origin and are derived from either the ventricular zone of the lateral ventricle or glioblasts (Kitamura et al., 1984; 
Paterson et al., 1973). Kitamura and colleagues (Kitamura et al., 1984) used 3H-thymidine autoradiographic analysis to investigate the genesis of microglia within the mouse hippocampus. They concluded that resting microglia originate from glioblasts, direct derivatives of matrix cells, that are of neuroectodermal origin. Interestingly, the possibility that microglia might be derived from the neuroectoderm via a mesenchymal stem cell type was supported by a recent publication (Takashima et al., 2007). Embryonic stem cells were cultivated and differentiated under two different conditions, one gave rise to mesodermal cells and the other one generated cells from the neuroectodermal lineage. Takashima and colleagues could show that mesenchymal stem cells (MSC) do not develop from mesodermal cells but from cells positive for Sox1, a molecular marker specifically expressed on neuroepithelial cells. They concluded that this way is representing the earliest recruitment of MSCs, whereas the origin of the later waves remains unsolved.

However, in 2002 it was shown that microglia express the transcription factor PU.1, which is myeloid specific. Therefore, it was suggested that prenatal microglia are derived from mesenchymal cells from the myeloid lineage (Rezaie and Male, 2002). Various monoclonal antibodies that are used to identify monocytes and macrophages like CD11b, CD45, CD68 and MHC class II also label microglia which supports the notion that microglia are derived from blood monocytes or another monocyte-related myeloid cell type. This view was further supported by the discovery that the first appearance of microglial cells coincide with the vascularization of the brain. It was suggested that circulating monocytes enter the nervous system and transform to microglia (Imamoto and Leblond, 1978; Ling, 1979) before the formation of the blood-brain-barrier has been completed (Perry et al., 1985). Infiltration of monocytes could be confirmed by carbon-labelling (Ling et al., 1980) and histochemical studies using marker enzymes for monocytes (Ferrer and Sarmiento, 1980; Ling et al., 1982). Andjelkovic and colleagues labelled microglia in the developing and adult human brain using lectin-histochemistry (Andjelkovic et al., 1998). Lectin positive cells can be subdivided into two groups which both exist in the adult brain, but show different distribution and time schedule of morphological changes. Their results support the consideration that there could be different origins of microglia.

Two questions remain to be answered: when do the first microglia appear and what is their origin. It has been established that microglial progenitors populate the nervous system during embryonic and fetal development (Rezaie and Male, 1999). Some authors have suggested the yolk sac as the tissue of origin for all tissue macrophages during embryonic development (Alliot et al., 1999; Kaur et al., 2001). Alliot and colleagues (1999) reported that cells with properties of microglial precursors can be first detected at embryonic day E8 in mice and that the majority of these progenitors originate from the yolk sac.

Nowadays, it is suggested that microglia populate the brain in two waves. The first one takes place in the neuroepithelium during embryonic development around E8-9 in rodents with unknown origin (Alliot et al., 1999). The second wave occurs in the brain during fetal development at E17-18. These cells are derived from a pool of circulating myeloid precursor cells of mesodermal origin (Chan et al., 2007).

In the adulthood, it is widely accepted that microglia invading the diseased CNS are derived from circulating monocytes originating in the bone marrow (Perry et al., 1985; Rezaie and Male, 2002). It was described that in bone marrow chimeric mice circulating monocytes are recruited to the lesion site of the brain and differentiate into microglia (Mildner et al., 2007). 
However, it seems that the inappropriate stimulus of irradiation is required for the recruitment (Mildner et al., 2007).

Microglial function is often studied on primary microglial cells, which are isolated and enriched from mixed glial cultures derived from the brains of postnatal mice or rats. But the cell number obtained by a shaking procedure from mixed glial culture flasks is rather low (Giulian and Baker, 1986). Optionally, a pure population of microglial cells can be obtained using a combination of density gradients and flow cytometric sorting (Ford et al., 1995). This methodology is applied to isolate both mouse and human microglia. However, the obtained number of primary microglia is very limited in rodents and humans. This aspect complicates classical biochemistry studies, systematic screening tests or cell therapy approaches. Therefore, the BV2 cell line which is originated from primary mouse microglia by oncogenetic transformation (Blasi et al., 1990; Bocchini et al., 1992) is used as a substitute for primary microglia. Murine cultured microglia are immortalized via injection with vraf/v-myc recombinant retroviruses. The obtained BV2 cells show properties like macrophages in terms of antigen profile and phagocytic capacity. However, due to the transformation process these cells show an altered cytokine profile and changes in their migratory capacity (Horvath et al., 2008; Napoli et al., 2009). Later on, Nagai and colleagues established an immortalized cell line of human microglia termed HMO6 (Nagai et al., 2005; Nagai et al., 2001). This cell line is developed from human embryonic telencephalon tissue by retroviral transformation with v-myc. Certainly, these cells can not be used in therapeutical approaches due to the usage of retroviruses for transformation. Therefore, microglia derived from embryonic stem (ES) cells might provide a new tool to study microglial function and to apply them for cellular therapies.

\section{Embryonic and induced pluripotent stem cell-derived microglia}

During the last decades a major breakthrough was the development of mouse pluripotent embryonic stem cell lines (Evans and Kaufman, 1981). These cells are isolated from the inner cell mass of embryos and can be cultivated in vitro on a feeder layer of mouse embryonic fibroblasts (MEF) in the presence of the leukemia inhibitory factor (LIF). In addition to the $\mathrm{MEF}$, which are supposed to secrete crucial factors to promote self-renewal, cultivated murine ES (mES) cell lines also require the presence of LIF to maintain their undifferentiated stage (Smith et al., 1988; Williams et al., 1988). In culture, mES cell lines show an almost unlimited proliferation capacity and maintain nearly a normal and stable karyotype (Smith, 2001). During cultivation ES cell lines do not loose their pluripotency and are able to generate all cell types of an embryo (Wobus and Boheler, 2005).

Due to their crucial role in neurodegenerative diseases microglia could be used as a cellular vehicle for gene or regenerative therapies in the CNS (Neumann, 2006). The CNS is delimited from the circulating blood by the blood-brain-barrier which controls the entry of substances and molecules. Theoretically, only $2 \%$ of small molecules are able to enter the CNS, whereas large molecules are unable to pass the blood-brain-barrier. Therefore, only a limited number of drugs can be introduced in CNS diseases. Microglial cells are a migratory cell type that is able to pass the blood-brain-barrier and could therefore be used as a vehicle to introduce therapeutical proteins into the CNS to the affected tissue.

As already discussed, the obtained number of primary microglia is very limited in rodents and humans using the before mentioned protocols. Contrary to these methods, the generation of microglia derived from pluripotent stem cells constitute a source of unlimited 
numbers of microglia which can be used for biochemical studies, systemic screening tests and cell therapy approaches. Recently, a protocol for the generation of microglia derived from mES cells was developed (Beutner et al., 2010; Napoli et al., 2009). This effort was initiated by a work from Tsuchiya and colleagues who succeeded in the differentiation of microglial-like cells derived from mES cells (Tsuchiya et al., 2005). During their neuronal differentiation based on a protocol for the generation of dopaminergic neurons (Lee et al., 2000) they found a population positive for Iba1 and CD45. Using a density gradient, these cells with morphological characteristics of primary microglia could be isolated. However, these isolated cells were not described to survive and proliferate. Thus, we generated a protocol to obtain microglial precursors from mES cells (Beutner et al., 2010; Napoli et al., 2009). These ES cell derived microglial precursors (ESdM) are stable proliferating in culture and have substantially most characteristics of primary microglia. The differentiation of mES cells to microglial precursors requires a five step protocol (Beutner et al., 2010). ES cells are cultivated on an irradiated MEF layer in defined medium in the presence of LIF. To induce spontaneous differentiation, ES cell clusters are detached and cultured on non-adherent culture dishes without LIF. So called embryoid bodies (EBs) are generated and plated on gelatine-coated cell culture dishes in ITS-medium supplemented with fibronectin. Under these conditions cells start to proliferate and different cell types develop. Most of these cells can be immunostained against the intermediate filament protein nestin which is mostly expressed by neuronal precursors. After 6 days in this selection stage medium is changed to N2-medium to expand cells in the presence of FGF2 and laminin for 6 more days. Withdrawal of FGF2 induces differentiation of neurons, astrocytes and oligodendrocytes (Beutner et al., 2010). Within this mixed cell culture cells with microglial morphology can be detected around three weeks after removal of FGF2. The proliferation of these cells can be enhanced through addition of granulocyte macrophage colony stimulating factor (GM-CSF). Microglial precursors are manually isolated and cultivated in N2-medium. They attach to the cell culture dish and typically follow an exponential growth rate. Expression of the marker Iba1 and CD68 indicate that the isolated cells are microglial precursor cells derived from mouse embryonic stem cells. Comparable to primary microglia ESdM show high expression of CD11b and CD45 (Beutner et al., 2010). Analysis of a4 integrin and $\beta 1$ integrin show high expression levels of these two integrins by ESdM and primary microglia. In contrast, the expression of CD34 and cKit which are both expressed on certain stem cell populations can not be confirmed indicating that ESdM cell lines lost their stem cell properties. Besides, ESdM show expression of B7.2, a costimulatory ligand that is expressed on antigen-presenting cells and that together with its receptor is responsible for T and B cell activation. In addition, a weak expression of major histocompatibility complex (MHC) class II which is also expressed on antigen-presenting cells can be confirmed. Up to passage 20 no relevant changes of the surface marker profile can be observed. However, from passage 25 onwards ESdM lines show a decreased expression of the analyzed markers indicating that the phenotype is not stable over very long proliferation periods.

A typical hallmark of microglia is the inducibility of pro-inflammatory cytokines and reactive oxygen species after stimulation. ESdM cell lines and primary microglia stimulated with lipopolysaccharide (LPS) show an upregulation of inducible nitric oxide synthase (iNOS) and interleukin $1 \beta$ (IL-1 $\beta$ ) transcript levels (Beutner et al., 2010; Napoli et al., 2009). Interferon- $\gamma$ (IFNY) stimulation results in an increase in iNOS transcripts in ESdM comparable to primary microglia whereas IL-1 $\beta$ gene transcription is almost not affected in both cell types. Furthermore, a chemokine assay determines that ESdM migrate towards the chemokine 
CX3CL1 in a dose-dependent manner (Beutner et al., 2010). Comparable to primary microglia, migration is significantly increased following a CX3CL1 gradient. The phagocytic capacity is an important aspect of microglia. After LPS stimulation ESdM show an increase in phagocytosis of microsphere beads in comparison to unstimulated cells (Beutner et al., 2010). In summary, ESdM show most characteristics of primary microglia and therefore can be seen as a new promising tool to study microglial function in vitro and in vivo.

In 2006, Takahashi and Yamanaka identified 24 potential candidate genes that were thought to be involved in maintaining pluripotency and self renewal of ES cells (Takahashi and Yamanaka, 2006). They showed that reprogramming of mouse embryonic fibroblasts to an embryonic-like state is possible after retroviral transduction with the four factors Oct4, Sox2, Klf4 and c-Myc. These so called induced pluripotent stem (iPS) cells showed similarities to ES cells in terms of morphology, proliferation and expression of pluripotency markers. Furthermore, iPS cells are able to differentiate into all three germ layers and therefore can be used to generate every cell type of the body. Some month later different groups succeeded in the generation of iPS cells from human adult fibroblasts (Takahashi et al., 2007b; Yu et al., 2007). Fibroblasts are obtained from human skin tissue biopsies and cultured under defined conditions. For reprogramming, human fibroblasts are retrovirally co-transduced with Oct4, Sox2, c-Myc and Klf4 genes. The obtained iPS cells are cultured according to protocols established for human embryonic stem cells. The analysis of iPS cells shows that they display a normal morphology, a normal karyotype and the expression of several pluripotency markers like Oct4, SSEA-3, SSEA-4, Tra-1-60 and Tra-1-81. Furthermore, multilineage differentiation of iPS cells is confirmed by embryoid body and teratoma formation. However, the generation of iPS cells using retroviruses includes the integration of genetic material and thereby the potential risk of genetic modifications of the target cells. To overcome this issue modified methods were developed to generate iPS cells (Yamanaka, 2009). Recently, it was shown that proteins conjugated with a short peptide mediating protein transduction can be directly delivered into the target cell. Using recombinant cell-penetrating reprogramming proteins, iPS cells are obtained from mouse fibroblasts (Zhou et al., 2009).

In a next step, human iPS cells are used for differentiation into microglial precursors (unpublished, pending European patent EP2010_055731). A differentiation protocol is applied with nearly the same five steps described for the generation of ESdM. Human iPS cells are cultured on a layer of irradiated MEF in the presence of FGF2. After some days in culture, iPS colonies can be detached and cultivated on non-adherent dishes without any growth factors to induce spontaneous differentiation. The resulting EBs are allowed to attach to the culture dish and grow out in defined medium supplemented with FGF2 and fibronectin. For expansion of the cells medium is changed to N2-medium in the presence of FGF2 and laminin. Withdrawal of the growth factor after some days induces the differentiation of microglial precursors identified by morphology. Microglial identity is confirmed using immunocytochemical analysis with antibodies against the microglial marker Iba1 and CD68. The iPS-derived microglial precursor (iPSdM) cells can be isolated and cultivated. Because disease-specific iPS cells (Dimos et al., 2008; Ebert et al., 2009; Soldner et al., 2009) can be generated, this method might represent a new tool for regenerative medicine for study and treatment of disease models.

\section{Target pathway identification and drug screening}

Drug discovery processes are costly in terms of time and expenses. High throughput rate screening technologies allow rapid testing of compounds, but might lack physiological 
conditions. Classically two distinct sources of human cell types, primary or immortalized cell lines, are available for drug screening technologies (Ebert and Svendsen, 2010). Primary cell lines are fully differentiated cell types with close approximation of native function, but often are inaccessible, require fresh preparation and have questionable reproducibility. In principal, primary microglial cell lines are not available due to the inaccessibility of the human brain tissue and difficulty to maintain the cells in culture.

In contrast, immortalized cell lines have low costs for maintenance and are homogenous cell populations, but lack important aspects of native cells such as certain metabolic or migratory functions. Furthermore, many cell types are not available as immortalized cell lines. In literature, a human immortalized microglia cell line was described (Nagai et al., 2005; Nagai et al., 2001). This cell line (HMO6) is developed from human embryonic telencephalon tissue by retroviral transformation with v-myc and is reported to possess most immunological and functional characteristics of primary microglia. However, in comparison to primary microglia, HMO6 cells display an altered cytokine profile (Nagai et al., 2001). Therefore, they probably do not fully reflect the properties of primary microglia.

Now, a new technology to obtain human microglial cells becomes available for drug screening technologies. As described above for microglia, embryonic stem cells or induced pluripotent stem cells can be differentiated into stably proliferating cell types. Most adult tissue cell types including microglia can be obtained at high quantities using this technology. The tissue cell types differentiated from stem cells show functional properties very close to the native cell types. Most interestingly, cell lines can be generated from diseased patients, too. However, reproducible methods to obtain fully differentiated cells and to achieve purified populations are still under development. As described above, microglial lines now can be generated from human induced pluripotent stem cells, which reflect very much the native function of primary microglia. The microglial lines can then be used for screening technologies.

One possible use of human microglial cell lines could be screening tests to evaluate the effect of new possible drugs or substances that might act toxic. Nanoparticles which are sized between 1 and $100 \mathrm{~nm}$ are basically of interest in pharmacy and medicine as the number of products containing synthesized nanoparticles steadily increases. Orally absorbed nanoparticles via drugs or food can pass the blood system via the gut. It was reported that silica crystals can activate immune cells, are phagocytosed and transported into the lysosome (Hornung et al., 2008). Given that these nanoparticles can not be digested, lysosomal swelling and damage might be induced in phagocytes including microglia. In addition, lysosomal damage activates the inflammasome and the release of the proinflammatory cytokine IL-1 $\beta$. It is expected that the size, structure and type of nanoparticles might influence this lysosomal toxicity. Interestingly, aggregated amyloid $\beta(A \beta)$ which is involved in the pathology of AD and exhibit a size of $10-200 \mathrm{~nm}$ can activate microglia in a similar way (Halle et al., 2008). Halle and colleagues demonstrated that microglia phagocytose fibrillar $A \beta$ and transport it into the lysosome, where it induces swelling and damage of this organelle. The inflammasome of microglia is activated which leads to the release of inflammatory mediators like IL-1 $\beta$. Furthermore, diesel exhaust particles (DEP) mediate the neurotoxicity on dopaminergic neurons caused by microglia, possibly by a similar mechanism (Block et al., 2004). Diesel exhaust particles uptake leads to the activation of microglia and their production of reactive oxygen species and nitric oxide, which induces toxicity of dopaminergic neurons. In summary, nanoparticles and other small particles principally have the risk to activate microglia leading to the release of pro-inflammatory 
cytokines and radicals which can promote the pathology of neurodegenerative diseases. Thus, microglial lines could help to evaluate the possible brain toxicity of very small particles.

Another possibility to use human microglial cell lines for screening is the development of novel drugs for neurodegenerative diseases. Activated microglia are reported to be involved in the pathology of neurodegenerative diseases such as amyotrophic lateral sclerosis (ALS). Approximately, $10-20 \%$ of patients with familiar ALS show a mutation in the superoxide dismutase-1 (SOD1) gene whose product is involved in the conversion of free superoxide radicals. In an animal model of ALS it was demonstrated that microglia with mutant SOD1 drive the disease onset and progression in particular via the release of pro-inflammatory molecules and radicals (Boillee and Cleveland, 2008). Mutant SOD1 stimulates the NADPH oxidase resulting in an overproduction of reactive oxygen species (ROS). Therefore, it is proposed that ROS produced by microglia mediate the pathogenesis of familiar ALS associated with a mutation of SOD1.

Human iPS-derived microglia cell lines would provide a new possibility to investigate the effect of different SOD1 mutations on the toxicity of microglia. Therefore, iPS-derived microglia could be transduced with mutant SOD1 or obtained from patients with a SOD1 mutation and analyzed for abnormal radical and pro-inflammatory cytokine production. Furthermore, co-culture of those genetically modified or mutated microglia and motor neurons could give more insight in the pathology of the disease.

Since iPS cells can be generated from diseased patients (Dimos et al., 2008; Ebert et al., 2009; Park et al., 2008) they represent a new tool for disease modelling screens of several neurodegenerative diseases. Ideally, iPS cells are expanded and differentiated in the disease relevant cell type such as microglia. The differentiated cell type would allow drug screening tests and investigations of genes differently regulated or mutated in this cell type.

In summary, iPS-derived microglia represent human conditions better than other cell lines, thus allowing drug screening and identification of pathways affected in neurodegenerative diseases.

\section{Combating cancer}

The most common and aggressive type of primary brain tumors in humans is the glioma, which most probably arises from glial cells or their progenitor cells. As primary tumors, gliomas occur rather rarely with an estimated prevalence of 15 cases for 100000 people (American Cancer Society, 2006). These anaplastic and malignant tumors result in a median of survival after diagnosis from 2 to 8 months, depending on the age of the patient (Curran et al., 1993; Scott and Mickle, 1987). One of the major problems in combating tumors is their ability to override the immune system. They are known to express a variety of immunosuppressive molecules like interleukin-10 (IL-10), prostaglandin E2 or transforming growth factor- $\beta$ (TGF $\beta$ ) (Wiendl et al., 2002; Wischhusen et al., 2002; Wrann et al., 1987). The secretion of these molecules leads to a local immunosuppression as well as to a systemic immunodeficiency (Platten et al., 2001).

The main treatment of glioma is surgical therapy, whereas the extent of the tumor resection closely correlates with the survival time of the patient (Jeremic et al., 2003; Keles and Berger, 2004; Soffietti et al., 1989). Nevertheless, brain surgery is not capable of removing all tumor cells. Thus, infiltrating tumor cells still reside in the healthy brain tissue and cause reformation of gliomas. Radiotherapy is another standard therapy for treatment of glioma. 
But, in respect to long term survival, no effect of radiation alone is found in case of grade II gliomas (Karim et al., 2002).

In addition to these treatments, chemotherapy is commonly used. Chemotherapy aims at the impairment of cell division, which mostly affects fast-dividing cells including tumor cells. One of the biggest disadvantages of this therapy is the side effect caused by the effects on healthy dividing cells, which leads to hair loss and damage of the intestinal epithelium (Krauseneck and Muller, 1994).

Still, those therapies do not result in a satisfactory therapy of gliomas and there is need for new therapeutical approaches.

Experimental therapies are aiming at several mechanisms in tumor progression. On a molecular level, therapies aim at the cancer specific signal cascades and molecules to influence proliferation, invasion and angiogenesis (Adjei and Hidalgo, 2005; Krause et al., 2005). One of the most promising targets is TGF $\beta$. Encouraging data of longer survival rates and slower tumor growth was obtained using a TGF $\beta$ antisense oligonucleotide for the treatment of human glioblastoma (Schlingensiepen et al., 2006). These findings were endowed by animal experiments and in vitro data (Jachimczak et al., 1996). The platelet derived growth factor receptor (PDGFR) is another possible candidate in molecular approaches of combating cancer. Upon inhibition of this receptor with imatinib, the tumor growth rate decreases and even complete remission can be observed in some patients (Dresemann, 2005).

Another approach in this field is the active specific immunotherapy which includes the in vivo induction of tumor-specific cytotoxic T lymphocytes. Upon induction, those cells are likely to be able to trigger apoptosis of tumor cells (Kagi et al., 1994).

During the recent years, focus has been cast on gene-based therapy in regard to malign gliomas. Mostly, adenoviral and retroviral vectors are used to deliver genes with therapeutic effects into the glioma site. The most promising candidates are oncolytic gene therapy and gene transfer of p53 or interferon- $\beta$ (IFN $\beta$ ) (Lang et al., 2003; Mineta et al., 1995; Yoshida and Tanaka, 2004). It was demonstrated that bone marrow derived cells express thymidine kinase of herpes simplex virus have a therapeutic effect on gliomas through bystandermediated glioma cell killing after gancyclovir application (Miletic et al., 2007).

Microglia are known to be attracted by and to infiltrate the glioma site (Umemura et al., 2008). However, their phagocytic ability, antigen presentation and secretion of proinflammatory cytokines is suppressed by the tumor cells (Hanisch and Kettenmann, 2007; Komohara et al., 2008; Yang et al., 2010). These tumor-infiltrating microglial cells obtain an immunosuppressive phenotype and promote TGF $\beta$ production via an autocrine loop (Umemura et al., 2008). In addition to the immunosuppressive cytokine milieu provided by the glioma cells, this leads to $\mathrm{T}$ cell tolerance and inactivation of tumor targeted immune responses (Carpentier and Meng, 2006). Nevertheless, microglia are potent immune effector cells and are able to mediate the innate and boost adaptive immune responses. It is known that the classical activated microglial cell, in contrast to the alternatively activated microglia with an immunosuppressive phenotype, could phagocytose glioma cells and furthermore create a pro-inflammatory milieu (Mantovani et al., 2004). Additionally, chemokines from microglia are known to attract cytotoxic cells such as natural killer cells (Carter et al., 2007; Hughes et al., 2002; Napoli and Neumann, 2009), they yield a high potential for immunostimulatory therapy approach. Clearly, microglia are situated ideally within the CNS to confront migrating and resident tumor cells. Another feature of microglia is their ability to migrate from the blood stream into the CNS, which makes them an interesting 
vehicle for therapeutic gene transfer into mature CNS tissue and the tumor residuum (Flugel et al., 2001).

Thus, the resolution of the immunosuppressive milieu by triggering a cytotoxic phenotype of microglia in the glioma site in combination with recruitment of cytotoxic leukocytes yields a promising approach. Especially microglial cells derived from embryonic stem cells appear suitable for therapy approaches, as they have unlimited proliferative potential and differentiated cells bear the potential to stimulate cytotoxicity towards glioma cells. Thus, iPSdM might therefore be a suitable and powerful tool for immune system-based or genetransfer-based cell therapy of human glioma.

\section{Regenerative approaches}

Microglial cells are the immune effector cells which mediate immune responses in the CNS. They are known to play crucial roles in several neurodegenerative diseases such as multiple sclerosis (MS), AD or PD. Thus, they are an interesting target for regenerative therapies.

In MS, the immune system reacts with a destructive immune response against antigens of the CNS like myelin basic protein (MBP) or myelin oligodendrocyte glycoprotein (MOG), which leads to demyelination and axonal injury (Mattson and Taub, 2004). During disease course, scar-like plaques appear around the damaged axons, called lesions (Chari, 2007). Additional to the process of demyelination, inflammation is a hallmark of MS. This inflammation is mainly mediated by activated T cells, which invade the brain via the bloodbrain-barrier and attack the myelin sheath of axons (Compston and Coles, 2002; Wucherpfennig and Strominger, 1995). This subsequently leads to stimulation of other immune cells like microglia and macrophages, which then secrete inflammatory cytokines (Cannella and Raine, 1995). This in turn leads to further recruitment of T cells, B cells and macrophages to the inflammation site (Steinman et al., 2002).

Until now, there is no known cure for MS, though some improvement in prevention of attacks and disability could be achieved through administration of immunosuppressants like interferons (Comi, 2009). Nevertheless, there is still need for other therapeutical approaches, especially in regard to neuroprotection and regeneration. Stem cell research has lead to new approaches in addressing neuroinflammatory disorders. Several cell types have been used for experimental therapies. Neural stem cells have been reported to migrate to inflammation sites in the CNS and to contribute to functional recovery and tissue repair (Pluchino et al., 2003). A similar beneficial effect was shown using bone marrow cells in experimental autoimmune encephalomyelitis (EAE), a mouse model for MS (Zappia et al., 2005).

It has been shown that microglia are able to pass the blood-brain-barrier and migrate into the brain under pathological conditions (Imai et al., 1997). In our group, we could show that ESdM like other bone marrow derived myeloid precursors migrate to lesion sites in EAE afflicted mice. Bone marrow myeloid precursors as putative progenitors of microglia have a beneficial impact after transduction with the microglial receptor triggering receptor expressed on myeloid cells-2 (TREM2) on the clinical course of EAE, on demyelination and axonal damage (Takahashi et al., 2007a). Furthermore, an anti-inflammatory milieu is established in the lesion sites due to the treatment (Takahashi et al., 2007a). Similar effects might be expected after transplantation of microglial precursor cells that are derived from ES cells and constitutively expressing TREM2.

As iPS-derived microglia principally can be generated from human iPS cells without oncogenic transformation and in high numbers, they might be a suitable and save vehicle 
for neurotrophic factors to be released at inflammatory lesions in MS. In regard to AD, microglia can be seen as a possible therapeutic target, too. The pathological hallmarks of $\mathrm{AD}$ are cortical atrophy with accumulation of extracellular deposits of amyloid $\beta(A \beta)$ in senile plaques and intracellular neurofibrillary tangles (NFT) of hyperphosphorylated tau in the cerebral cortex (De Strooper and Annaert, 2000). It is known that A $\beta$ serves as a microglial activator and leads to production of various inflammatory mediators (Benveniste et al., 2001). On the other hand, a neuroprotective role of microglia was found in AD. Activated microglia migrate to $A \beta$ plaques, where they release proteolytic enzymes like metalloproteinases that degrade A $\beta$ (Qiu et al., 1997). Although it is unclear why microglia fail to completely clear the $A \beta$ plaques by phagocytosis, at least they appear to restrict plaque growth (Bolmont et al., 2008). Nevertheless, it was reported that administration of exogenously applied microglia in a rat animal model of AD increases $\mathrm{A} \beta$ clearance (Takata et al., 2007). It has been shown by several groups that bone marrow-derived cells are capable of becoming brain macrophages, which then might play a major role in A $\beta$ clearance (Malm et al., 2005; Simard and Rivest, 2004). Therefore, microglial cells may be a suitable tool for clinical application, if they are able to overcome the blood-brain-barrier. This problem could be addressed by irradiation (Ajami et al., 2007) or by intra-arterial injection (Imai et al., 1997), which both facilitates the entry of microglia into the brain. Otherwise, it would be possible to directly apply the iPS-derived microglia into the CNS by local transplantation. Thus, iPS-derived microglia might broaden the therapeutical approaches in AD, as they might be able to clear $A \beta$ plaques and attenuate disease course.

\section{Conclusion}

Microglia are involved in a variety of neurodegenerative diseases. They are a promising target for new therapies. Their role as immune effector cells in the CNS might yield interesting perspectives for locally modulating the cytokine milieu or phagocytic properties to influence the disease course in a beneficial way. Glioma is the most common brain tumor which is not curable so far. Microglia were demonstrated to phagocytose glioma cells and attract cytotoxic cells to the glioma site. Therefore, they display a high potential for usage in therapy. In addition, microglia were shown to migrate from the blood stream into the CNS which makes them a suitable cellular vehicle for therapeutic gene transfer. Microglia overexpressing neurotrophic factors could contribute to the regeneration of lesioned brain tissue. Therefore, the generation of microglia from embryonic stem cells and iPS cells provides a new technology for combating cancer and for usage in regenerative medicine. Since iPS-derived microglia resemble human primary cells they can be further used in drug screening tests. It has been shown that very small sized particles such as nanoparticles could principally activate microglia. This leads to the production of pro-inflammatory cytokines and radicals by microglia which in turns promotes the pathology of neurodegenerative diseases. Therefore, iPS-derived microglia provide a new tool to evaluate the possible toxicity of very small-sized particles to the CNS.

\section{Acknowledgements}

The Neural Regeneration Group at the University of Bonn Life \& Brain Center is supported by the Hertie Foundation, the Walter und Ilse Rose Foundation, the Deutsche Forschungsgemeinschaft (FOR1336, KFO177, SFB704) and the EU (LSHM-CT-2005-018637). 
We thank J. Schumacher and R. Hass for excellent technical support of cultures and molecular biology.

\section{Conflict of interest}

K.R. and H.N. have interest in royalty rights on a pending European patent EP2010_055731, Method for obtaining human microglial precursor cells from pluripotent stem cells'. H.N has interest in royalty rights on a pending European patent EP2010_055725 ,Microglial precursor cells for the treatment of malignant neoplasms of the central nervous system'.

\section{References}

Adjei AA, Hidalgo M. Treating cancer by blocking cell signals. J Clin Oncol, 2005; 23: 527980.

Ajami B, Bennett JL, Krieger C, Tetzlaff W, Rossi FM. Local self-renewal can sustain CNS microglia maintenance and function throughout adult life. Nat Neurosci, 2007; 10: 1538-43.

Alliot F, Godin I, Pessac B. Microglia derive from progenitors, originating from the yolk sac, and which proliferate in the brain. Brain Res Dev Brain Res, 1999; 117: 145-52.

Andjelkovic AV, Nikolic B, Pachter JS, Zecevic N. Macrophages/microglial cells in human central nervous system during development: an immunohistochemical study. Brain Res, 1998; 814: 13-25.

Arnold SJ, Robertson EJ. Making a commitment: cell lineage allocation and axis patterning in the early mouse embryo. Nat Rev Mol Cell Biol, 2009; 10: 91-103.

Benveniste EN, Nguyen VT, O'Keefe GM. Immunological aspects of microglia: relevance to Alzheimer's disease. Neurochem Int, 2001; 39: 381-91.

Beutner C, Roy K, Linnartz B, Napoli I, Neumann H. Generation of microglial cells from mouse embryonic stem cells. Nat Protoc, 2010; 5: 1481-94.

Blasi E, Barluzzi R, Bocchini V, Mazzolla R, Bistoni F. Immortalization of murine microglial cells by a v-raf/v-myc carrying retrovirus. J Neuroimmunol, 1990; 27: 229-37.

Block ML, Hong JS. Microglia and inflammation-mediated neurodegeneration: multiple triggers with a common mechanism. Prog Neurobiol, 2005; 76: 77-98.

Block ML, Wu X, Pei Z, Li G, Wang T, Qin L, Wilson B, Yang J, Hong JS, Veronesi B. Nanometer size diesel exhaust particles are selectively toxic to dopaminergic neurons: the role of microglia, phagocytosis, and NADPH oxidase. FASEB J, 2004; 18: 1618-20.

Block ML, Zecca L, Hong JS. Microglia-mediated neurotoxicity: uncovering the molecular mechanisms. Nat Rev Neurosci, 2007; 8: 57-69.

Bocchini V, Mazzolla R, Barluzzi R, Blasi E, Sick P, Kettenmann H. An immortalized cell line expresses properties of activated microglial cells. J Neurosci Res, 1992; 31: 616-21.

Boillee S, Cleveland DW. Revisiting oxidative damage in ALS: microglia, Nox, and mutant SOD1. J Clin Invest, 2008; 118: 474-8.

Bolmont T, Haiss F, Eicke D, Radde R, Mathis CA, Klunk WE, Kohsaka S, Jucker M, Calhoun ME. Dynamics of the microglial/amyloid interaction indicate a role in plaque maintenance. J Neurosci, 2008; 28: 4283-92.

Cannella B, Raine CS. The adhesion molecule and cytokine profile of multiple sclerosis lesions. Ann Neurol, 1995; 37: 424-35. 
Carpentier AF, Meng Y. Recent advances in immunotherapy for human glioma. Curr Opin Oncol, 2006; 18: 631-6.

Carter SL, Muller M, Manders PM, Campbell IL. Induction of the genes for Cxc19 and Cxcl10 is dependent on IFN-gamma but shows differential cellular expression in experimental autoimmune encephalomyelitis and by astrocytes and microglia in vitro. Glia, 2007; 55: 1728-39.

Chan WY, Kohsaka S, Rezaie P. The origin and cell lineage of microglia: new concepts. Brain Res Rev, 2007; 53: 344-54.

Chari DM. Remyelination in multiple sclerosis. Int Rev Neurobiol, 2007; 79: 589-620.

Comi G. Shifting the paradigm toward earlier treatment of multiple sclerosis with interferon beta. Clin Ther, 2009; 31: 1142-57.

Compston A, Coles A. Multiple sclerosis. Lancet, 2002; 359: 1221-31.

Curran WJ, Jr., Scott CB, Horton J, Nelson JS, Weinstein AS, Fischbach AJ, Chang CH, Rotman M, Asbell SO, Krisch RE, et al. Recursive partitioning analysis of prognostic factors in three Radiation Therapy Oncology Group malignant glioma trials. J Natl Cancer Inst, 1993; 85: 704-10.

De Strooper B, Annaert W. Proteolytic processing and cell biological functions of the amyloid precursor protein. J Cell Sci, 2000; 113 ( Pt 11): 1857-70.

del Rio-Hortega P. Art and artifice in the science of histology. 1933. Histopathology, 1933; 22: 515-25.

Dimos JT, Rodolfa KT, Niakan KK, Weisenthal LM, Mitsumoto H, Chung W, Croft GF, Saphier G, Leibel R, Goland R, Wichterle H, Henderson CE, Eggan K. Induced pluripotent stem cells generated from patients with ALS can be differentiated into motor neurons. Science, 2008; 321: 1218-21.

Dresemann G. Imatinib and hydroxyurea in pretreated progressive glioblastoma multiforme: a patient series. Ann Oncol, 2005; 16: 1702-8.

Ebert AD, Svendsen CN. Human stem cells and drug screening: opportunities and challenges. Nat Rev Drug Discov, 2010; 9: 367-72.

Ebert AD, Yu J, Rose FF, Jr., Mattis VB, Lorson CL, Thomson JA, Svendsen CN. Induced pluripotent stem cells from a spinal muscular atrophy patient. Nature, 2009; 457: 277-80.

Evans MJ, Kaufman MH. Establishment in culture of pluripotential cells from mouse embryos. Nature, 1981; 292: 154-6.

Ferrer I, Sarmiento J. Nascent microglia in the developing brain. Acta Neuropathol, 1980; 50: 61-7.

Flugel A, Berkowicz T, Ritter T, Labeur M, Jenne DE, Li Z, Ellwart JW, Willem M, Lassmann $\mathrm{H}$, Wekerle H. Migratory activity and functional changes of green fluorescent effector cells before and during experimental autoimmune encephalomyelitis. Immunity, 2001; 14: 547-60.

Ford AL, Goodsall AL, Hickey WF, Sedgwick JD. Normal adult ramified microglia separated from other central nervous system macrophages by flow cytometric sorting. Phenotypic differences defined and direct ex vivo antigen presentation to myelin basic protein-reactive CD4+ T cells compared. J Immunol, 1995; 154: 430921.

Giulian D, Baker TJ. Characterization of ameboid microglia isolated from developing mammalian brain. J Neurosci, 1986; 6: 2163-78. 
Halle A, Hornung V, Petzold GC, Stewart CR, Monks BG, Reinheckel T, Fitzgerald KA, Latz E, Moore KJ, Golenbock DT. The NALP3 inflammasome is involved in the innate immune response to amyloid-beta. Nat Immunol, 2008; 9: 857-65.

Hanisch UK, Kettenmann H. Microglia: active sensor and versatile effector cells in the normal and pathologic brain. Nat Neurosci, 2007; 10: 1387-94.

Hornung V, Bauernfeind F, Halle A, Samstad EO, Kono H, Rock KL, Fitzgerald KA, Latz E. Silica crystals and aluminum salts activate the NALP3 inflammasome through phagosomal destabilization. Nat Immunol, 2008; 9: 847-56.

Horvath RJ, Nutile-McMenemy N, Alkaitis MS, Deleo JA. Differential migration, LPSinduced cytokine, chemokine, and NO expression in immortalized BV-2 and HAPI cell lines and primary microglial cultures. J Neurochem, 2008; 107: 557-69.

Hughes PM, Botham MS, Frentzel S, Mir A, Perry VH. Expression of fractalkine (CX3CL1) and its receptor, $\mathrm{CX} 3 \mathrm{CR} 1$, during acute and chronic inflammation in the rodent CNS. Glia, 2002; 37: 314-27.

Imai T, Hieshima K, Haskell C, Baba M, Nagira M, Nishimura M, Kakizaki M, Takagi S, Nomiyama H, Schall TJ, Yoshie O. Identification and molecular characterization of fractalkine receptor CX3CR1, which mediates both leukocyte migration and adhesion. Cell, 1997; 91: 521-30.

Imamoto K, Leblond CP. Radioautographic investigation of gliogenesis in the corpus callosum of young rats. II. Origin of microglial cells. J Comp Neurol, 1978; 180: 13963.

Jachimczak P, Hessdorfer B, Fabel-Schulte K, Wismeth C, Brysch W, Schlingensiepen KH, Bauer A, Blesch A, Bogdahn U. Transforming growth factor-beta-mediated autocrine growth regulation of gliomas as detected with phosphorothioate antisense oligonucleotides. Int J Cancer, 1996; 65: 332-7.

Jeremic B, Milicic B, Grujicic D, Dagovic A, Aleksandrovic J. Multivariate analysis of clinical prognostic factors in patients with glioblastoma multiforme treated with a combined modality approach. J Cancer Res Clin Oncol, 2003; 129: 477-84.

Kagi D, Vignaux F, Ledermann B, Burki K, Depraetere V, Nagata S, Hengartner H, Golstein $\mathrm{P}$. Fas and perforin pathways as major mechanisms of T cell-mediated cytotoxicity. Science, 1994; 265: 528-30.

Karim AB, Afra D, Cornu P, Bleehan N, Schraub S, De Witte O, Darcel F, Stenning S, Pierart M, Van Glabbeke M. Randomized trial on the efficacy of radiotherapy for cerebral low-grade glioma in the adult: European Organization for Research and Treatment of Cancer Study 22845 with the Medical Research Council study BRO4: an interim analysis. Int J Radiat Oncol Biol Phys, 2002; 52: 316-24.

Kaur C, Hao AJ, Wu CH, Ling EA. Origin of microglia. Microsc Res Tech, 2001; 54: 2-9.

Keles GE, Berger MS. Advances in neurosurgical technique in the current management of brain tumors. Semin Oncol, 2004; 31: 659-65.

Kitamura T, Miyake T, Fujita S. Genesis of resting microglia in the gray matter of mouse hippocampus. J Comp Neurol, 1984; 226: 421-33.

Komohara Y, Ohnishi K, Kuratsu J, Takeya M. Possible involvement of the M2 antiinflammatory macrophage phenotype in growth of human gliomas. J Pathol, 2008; 216: 15-24.

Krause M, Wohlfarth J, Georgi B, Pimentel N, Dorner D, Zips D, Eicheler W, Hessel F, Short SC, Joiner MC, Baumann M. Low-dose hyperradiosensitivity of human 
glioblastoma cell lines in vitro does not translate into improved outcome of ultrafractionated radiotherapy in vivo. Int J Radiat Biol, 2005; 81: 751-8.

Krauseneck P, Muller B. Chemotherapy of malignant gliomas. Recent Results Cancer Res, 1994; 135: 135-47.

Lang FF, Bruner JM, Fuller GN, Aldape K, Prados MD, Chang S, Berger MS, McDermott MW, Kunwar SM, Junck LR, Chandler W, Zwiebel JA, Kaplan RS, Yung WK. Phase I trial of adenovirus-mediated p53 gene therapy for recurrent glioma: biological and clinical results. J Clin Oncol, 2003; 21: 2508-18.

Lee SH, Lumelsky N, Studer L, Auerbach JM, McKay RD. Efficient generation of midbrain and hindbrain neurons from mouse embryonic stem cells. Nat Biotechnol, 2000; 18: 675-9.

Ling EA. Transformation of monocytes into amoeboid microglia in the corpus callosum of postnatal rats, as shown by labelling monocytes by carbon particles. J Anat, 1979; 128: 847-58.

Ling EA, Kaur C, Wong WC. Light and electron microscopic demonstration of non-specific esterase in amoeboid microglial cells in the corpus callosum in postnatal rats: a cytochemical link to monocytes. J Anat, 1982; 135: 385-94.

Ling EA, Penney D, Leblond CP. Use of carbon labeling to demonstrate the role of blood monocytes as precursors of the 'ameboid cells' present in the corpus callosum of postnatal rats. J Comp Neurol, 1980; 193: 631-57.

Malm TM, Koistinaho M, Parepalo M, Vatanen T, Ooka A, Karlsson S, Koistinaho J. Bonemarrow-derived cells contribute to the recruitment of microglial cells in response to beta-amyloid deposition in APP/PS1 double transgenic Alzheimer mice. Neurobiol Dis, 2005; 18: 134-42.

Mantovani A, Sica A, Sozzani S, Allavena P, Vecchi A, Locati M. The chemokine system in diverse forms of macrophage activation and polarization. Trends Immunol, 2004; 25: 677-86.

Mattson MP, Taub DD. Ancient viral protein enrages astrocytes in multiple sclerosis. Nat Neurosci, 2004; 7: 1021-3.

Mildner A, Schmidt H, Nitsche M, Merkler D, Hanisch UK, Mack M, Heikenwalder M, Bruck W, Priller J, Prinz M. Microglia in the adult brain arise from Ly-6ChiCCR2+ monocytes only under defined host conditions. Nat Neurosci, 2007; 10: 1544-53.

Miletic H, Fischer YH, Giroglou T, Rueger MA, Winkeler A, Li H, Himmelreich U, Stenzel W, Jacobs AH, von Laer D. Normal brain cells contribute to the bystander effect in suicide gene therapy of malignant glioma. Clin Cancer Res, 2007; 13: 6761-8.

Mineta T, Rabkin SD, Yazaki T, Hunter WD, Martuza RL. Attenuated multi-mutated herpes simplex virus-1 for the treatment of malignant gliomas. Nat Med, 1995; 1: 938-43.

Nagai A, Mishima S, Ishida Y, Ishikura H, Harada T, Kobayashi S, Kim SU. Immortalized human microglial cell line: phenotypic expression. J Neurosci Res, 2005; 81: 342-8.

Nagai A, Nakagawa E, Hatori K, Choi HB, McLarnon JG, Lee MA, Kim SU. Generation and characterization of immortalized human microglial cell lines: expression of cytokines and chemokines. Neurobiol Dis, 2001; 8: 1057-68.

Napoli I, Kierdorf K, Neumann H. Microglial precursors derived from mouse embryonic stem cells. Glia, 2009; 57: 1660-71.

Napoli I, Neumann H. Microglial clearance function in health and disease. Neuroscience, 2009; 158: 1030-8. 
Neumann H. Microglia: a cellular vehicle for CNS gene therapy. J Clin Invest, 2006; 116: 2857-60.

Nimmerjahn A, Kirchhoff F, Helmchen F. Resting microglial cells are highly dynamic surveillants of brain parenchyma in vivo. Science, 2005; 308: 1314-8.

Park IH, Arora N, Huo H, Maherali N, Ahfeldt T, Shimamura A, Lensch MW, Cowan C, Hochedlinger K, Daley GQ. Disease-specific induced pluripotent stem cells. Cell, 2008; 134: 877-86.

Paterson JA, Privat A, Ling EA, Leblond CP. Investigation of glial cells in semithin sections. 3. Transformation of subependymal cells into glial cells, as shown by radioautography after $3 \mathrm{H}$-thymidine injection into the lateral ventricle of the brain of young rats. J Comp Neurol, 1973; 149: 83-102.

Perry VH, Hume DA, Gordon S. Immunohistochemical localization of macrophages and microglia in the adult and developing mouse brain. Neuroscience, 1985; 15: 313-26.

Platten M, Wick W, Weller M. Malignant glioma biology: role for TGF-beta in growth, motility, angiogenesis, and immune escape. Microsc Res Tech, 2001; 52: 401-10.

Pluchino S, Quattrini A, Brambilla E, Gritti A, Salani G, Dina G, Galli R, Del Carro U, Amadio S, Bergami A, Furlan R, Comi G, Vescovi AL, Martino G. Injection of adult neurospheres induces recovery in a chronic model of multiple sclerosis. Nature, 2003; 422: 688-94.

Qiu WQ, Ye Z, Kholodenko D, Seubert P, Selkoe DJ. Degradation of amyloid beta-protein by a metalloprotease secreted by microglia and other neural and non-neural cells. J Biol Chem, 1997; 272: 6641-6.

Rezaie P, Male D. Colonisation of the developing human brain and spinal cord by microglia: a review. Microsc Res Tech, 1999; 45: 359-82.

Rezaie P, Male D. Mesoglia \& microglia--a historical review of the concept of mononuclear phagocytes within the central nervous system. J Hist Neurosci, 2002; 11: 325-74.

Rock RB, Gekker G, Hu S, Sheng WS, Cheeran M, Lokensgard JR, Peterson PK. Role of microglia in central nervous system infections. Clin Microbiol Rev, 2004; 17: 942-64, table of contents.

Schlingensiepen KH, Schlingensiepen R, Steinbrecher A, Hau P, Bogdahn U, Fischer-Blass B, Jachimczak P. Targeted tumor therapy with the TGF-beta 2 antisense compound AP 12009. Cytokine Growth Factor Rev, 2006; 17: 129-39.

Scott EW, Mickle JP. Pediatric diencephalic gliomas--a review of 18 cases. Pediatr Neurosci, 1987; 13: 225-32.

Simard AR, Rivest S. Bone marrow stem cells have the ability to populate the entire central nervous system into fully differentiated parenchymal microglia. Faseb J, 2004; 18: 998-1000.

Smith AG. Embryo-derived stem cells: of mice and men. Annu Rev Cell Dev Biol, 2001; 17: 435-62.

Smith AG, Heath JK, Donaldson DD, Wong GG, Moreau J, Stahl M, Rogers D. Inhibition of pluripotential embryonic stem cell differentiation by purified polypeptides. Nature, 1988; 336: 688-90.

Soffietti R, Chio A, Giordana MT, Vasario E, Schiffer D. Prognostic factors in welldifferentiated cerebral astrocytomas in the adult. Neurosurgery, 1989; 24: 686-92. 
Soldner F, Hockemeyer D, Beard C, Gao Q, Bell GW, Cook EG, Hargus G, Blak A, Cooper O, Mitalipova M, Isacson O, Jaenisch R. Parkinson's disease patient-derived induced pluripotent stem cells free of viral reprogramming factors. Cell, 2009; 136: 964-77.

Steinman L, Martin R, Bernard C, Conlon P, Oksenberg JR. Multiple sclerosis: deeper understanding of its pathogenesis reveals new targets for therapy. Annu Rev Neurosci, 2002; 25: 491-505.

Streit WJ. Microglia as neuroprotective, immunocompetent cells of the CNS. Glia, 2002; 40: 133-9.

Takahashi K, Prinz M, Stagi M, Chechneva O, Neumann H. TREM2-transduced myeloid precursors mediate nervous tissue debris clearance and facilitate recovery in an animal model of multiple sclerosis. PLoS Med, 2007a; 4: e124.

Takahashi K, Tanabe K, Ohnuki M, Narita M, Ichisaka T, Tomoda K, Yamanaka S. Induction of pluripotent stem cells from adult human fibroblasts by defined factors. Cell, 2007b; 131: 861-72.

Takahashi K, Yamanaka S. Induction of pluripotent stem cells from mouse embryonic and adult fibroblast cultures by defined factors. Cell, 2006; 126: 663-76.

Takashima Y, Era T, Nakao K, Kondo S, Kasuga M, Smith AG, Nishikawa S. Neuroepithelial cells supply an initial transient wave of MSC differentiation. Cell, 2007; 129: 137788.

Takata K, Kitamura Y, Yanagisawa D, Morikawa S, Morita M, Inubushi T, Tsuchiya D, Chishiro S, Saeki M, Taniguchi T, Shimohama S, Tooyama I. Microglial transplantation increases amyloid-beta clearance in Alzheimer model rats. FEBS Lett, 2007; 581: 475-8.

Tsuchiya T, Park KC, Toyonaga S, Yamada SM, Nakabayashi H, Nakai E, Ikawa N, Furuya M, Tominaga A, Shimizu K. Characterization of microglia induced from mouse embryonic stem cells and their migration into the brain parenchyma. J Neuroimmunol, 2005; 160: 210-8.

Umemura N, Saio M, Suwa T, Kitoh Y, Bai J, Nonaka K, Ouyang GF, Okada M, Balazs M, Adany R, Shibata T, Takami T. Tumor-infiltrating myeloid-derived suppressor cells are pleiotropic-inflamed monocytes/macrophages that bear M1- and M2-type characteristics. J Leukoc Biol, 2008; 83: 1136-44.

Wiendl H, Mitsdoerffer M, Hofmeister V, Wischhusen J, Bornemann A, Meyermann R, Weiss EH, Melms A, Weller M. A functional role of HLA-G expression in human gliomas: an alternative strategy of immune escape. J Immunol, 2002; 168: 4772-80.

Williams RL, Hilton DJ, Pease S, Willson TA, Stewart CL, Gearing DP, Wagner EF, Metcalf D, Nicola NA, Gough NM. Myeloid leukaemia inhibitory factor maintains the developmental potential of embryonic stem cells. Nature, 1988; 336: 684-7.

Wischhusen J, Jung G, Radovanovic I, Beier C, Steinbach JP, Rimner A, Huang H, Schulz JB, Ohgaki H, Aguzzi A, Rammensee HG, Weller M. Identification of CD70-mediated apoptosis of immune effector cells as a novel immune escape pathway of human glioblastoma. Cancer Res, 2002; 62: 2592-9.

Wobus AM, Boheler KR. Embryonic stem cells: prospects for developmental biology and cell therapy. Physiol Rev, 2005; 85: 635-78.

Wrann M, Bodmer S, de Martin R, Siepl C, Hofer-Warbinek R, Frei K, Hofer E, Fontana A. T cell suppressor factor from human glioblastoma cells is a $12.5-\mathrm{kd}$ protein closely related to transforming growth factor-beta. EMBO J, 1987; 6: 1633-6. 
Wucherpfennig KW, Strominger JL. Selective binding of self peptides to disease-associated major histocompatibility complex (MHC) molecules: a mechanism for MHC-linked susceptibility to human autoimmune diseases. J Exp Med, 1995; 181: 1597-601.

Yamanaka S. A fresh look at iPS cells. Cell, 2009; 137: 13-7.

Yang I, Han SJ, Kaur G, Crane C, Parsa AT. The role of microglia in central nervous system immunity and glioma immunology. J Clin Neurosci, 2010; 17: 6-10.

Yoshida S, Tanaka R. Generation of a human leukocyte antigen-A24-restricted antitumor cell with the use of SART-1 peptide and dendritic cells in patients with malignant brain tumors. J Lab Clin Med, 2004; 144: 201-7.

Yu J, Vodyanik MA, Smuga-Otto K, Antosiewicz-Bourget J, Frane JL, Tian S, Nie J, Jonsdottir GA, Ruotti V, Stewart R, Slukvin, II, Thomson JA. Induced pluripotent stem cell lines derived from human somatic cells. Science, 2007; 318: 1917-20.

Zappia E, Casazza S, Pedemonte E, Benvenuto F, Bonanni I, Gerdoni E, Giunti D, Ceravolo A, Cazzanti F, Frassoni F, Mancardi G, Uccelli A. Mesenchymal stem cells ameliorate experimental autoimmune encephalomyelitis inducing T-cell anergy. Blood, 2005; 106: 1755-61.

Zhou H, Wu S, Joo JY, Zhu S, Han DW, Lin T, Trauger S, Bien G, Yao S, Zhu Y, Siuzdak G, Scholer HR, Duan L, Ding S. Generation of induced pluripotent stem cells using recombinant proteins. Cell Stem Cell, 2009; 4: 381-4. 


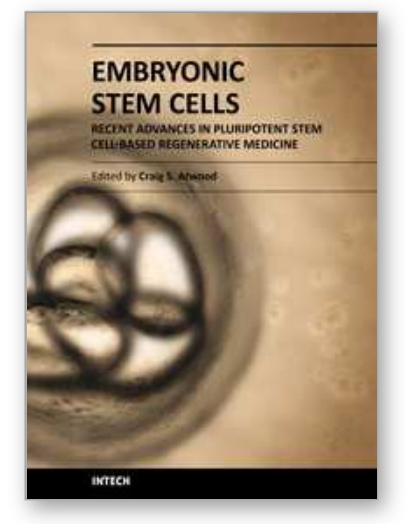

\section{Embryonic Stem Cells - Recent Advances in Pluripotent Stem Cell- Based Regenerative Medicine}

Edited by Prof. Craig Atwood

ISBN 978-953-307-198-5

Hard cover, 410 pages

Publisher InTech

Published online 26, April, 2011

Published in print edition April, 2011

Pluripotent stem cells have the potential to revolutionise medicine, providing treatment options for a wide range of diseases and conditions that currently lack therapies or cures. This book describes recent advances in the generation of tissue specific cell types for regenerative applications, as well as the obstacles that need to be overcome in order to recognize the potential of these cells.

\section{How to reference}

In order to correctly reference this scholarly work, feel free to copy and paste the following:

Kristin Roy, Clara Beutner and Harald Neumann (2011). Perspectives of Stem Cell-Derived Microglia for Medicine, Embryonic Stem Cells - Recent Advances in Pluripotent Stem Cell-Based Regenerative Medicine, Prof. Craig Atwood (Ed.), ISBN: 978-953-307-198-5, InTech, Available from:

http://www.intechopen.com/books/embryonic-stem-cells-recent-advances-in-pluripotent-stem-cell-basedregenerative-medicine/perspectives-of-stem-cell-derived-microglia-for-medicine

\section{INTECH}

open science | open minds

\section{InTech Europe}

University Campus STeP Ri

Slavka Krautzeka 83/A

51000 Rijeka, Croatia

Phone: +385 (51) 770447

Fax: +385 (51) 686166

www.intechopen.com

\section{InTech China}

Unit 405, Office Block, Hotel Equatorial Shanghai

No.65, Yan An Road (West), Shanghai, 200040, China

中国上海市延安西路65号上海国际贵都大饭店办公楼 405 单元

Phone: +86-21-62489820

Fax: $+86-21-62489821$ 
(C) 2011 The Author(s). Licensee IntechOpen. This chapter is distributed under the terms of the Creative Commons Attribution-NonCommercialShareAlike-3.0 License, which permits use, distribution and reproduction for non-commercial purposes, provided the original is properly cited and derivative works building on this content are distributed under the same license. 